\title{
Sex of Study Group
}

National Cancer Institute

\section{Source}

National Cancer Institute. Sex of Study Group. NCI Thesaurus. Code C49696.

The specific sex, either male, female, or mixed of the subject group being studied. 